\title{
Experimental study on injection characteristics of diesel-bioethanol fuel blends
}

\author{
This article presents the test results of injection processes of diesel-bioethanol fuel blends on a high pressure common \\ rail injection system. The injection characteristics were analyzed using the injection rate measuring instrumentation. The \\ injection rate, cycle injection quantity, injection delay and injection duration were analyzed across a range of injection \\ pressure and injection energizing time. As the results show, the peak injection rate and delay of diesel-ethanol blends \\ are lower compared to diesel fuel. The injection duration and discharge coefficients of diesel-ethanol blends were lower \\ than those of diesel fuel. It was observed that fuel density and fuel viscosity have significant influence on the injection \\ characteristics.
}

Key words: diesel fuel, ethanol-diesel blend, common rail injection system, injection rate, discharge coefficient

\section{Introduction}

For disorderly fossil fuel production and its intensive use in the world are decreasing crude oil reserves. In the current context, it becomes more important to look for alternative or renewable fuels, which harmoniously correlate with sustainable development, energy saving efficiency and environmental protection. On the other hand, this necessity is also stipulated by environmental requirements. In the European Union (EU), vehicles exhaust approximately 21\% of all gases causing greenhouse effect and the amount is constantly growing. Therefore, in its "White Paper", which provides a roadmap to a single European transport area, the European Commission mentions a $60 \%$ reduction of contaminants emission in the transport sector as one of the directions of development and use of sustainable types of fuel and increase of energy consumption efficiency by all types of vehicles [1].

Transport and agriculture sectors are among the largest consumers of mineral fuels, contributing the environmental pollution. The EU encourages and supports the production and consumption of biofuels, therefore EU countries have committed to the promotion of biofuels or other renewable fuels instead of gasoline or diesel fuel in the transport sector. The existing European Commission Directive 2009/28/EC calls on member states by 2020 to replace $10 \%$ of transport fuel consumption by biofuels. In the European Union, rapeseed oil remains the main raw material used in the production of biodiesel. In order to expand the base of raw materials and to increase the share of renewable energy in diesel fuel, recently interest in the potential use of bio-ethanol in diesel engines increased. Bio-ethanol can be produced from a number of crops, including sugarcane, corn (maze), wheat and sugar beet. The last two are currently the main sources of ethanol in Europe [3].

Experimental studies of the diesel-ethanol fuel blends on engine performance and exhaust emissions in diesel engines have been carried out by many researchers $[6,7]$. The fuel properties of the diesel-ethanol blends change the fuel injection, atomization and combustion characteristics and thus the exhaust emissions. The test conducted by scientists show that the ethanol additive in diesel fuel increases fuel consumption and thermal efficiency of the engine [8, 9]. Chemical structure and injection characteristics of fuel significantly affect the autoignition delay, since they influence the change of temperature of the mixture at the end of pressure period before the upper endpoint. Experimental tests have shown that ethanol prolongs the autoignition delay and increases the maximum gas pressure inside the cylinder [5]. Therefore, in order to better identify the effect of fuel properties on the diesel combustion process, phase's prior need investigated injection process and flow characteristics. Mixtures of ethanol and diesel fuels are characterized by lower biofuel viscosity, density, surface tension than diesel. These differences have a significant influence on injections and spray formations characteristics. The experimental studies of influence of biodiesel fuel properties on the injection mass flow rate of a diesel common-rail injection system have been carried out by Boudy and Seers [4]. The results show that fuel density is the main property that affects the injection process, such as total mass injected and pressure wave in the common rail system. Blends of ethanol and diesel fuels demonstrate a lower viscosity of biofuels [10]. Decrease in fuel viscosity changes the injection spray parameters, decreases spray penetration and increases its initial angle. According to Chakravarthy et al. [11] physical properties of biofuel is a function of temperature, observing that the density, surface tension, and kinematic viscosity of biodiesel are higher than diesel, whereas the vapour pressure and heat capacity are lower. These differences have a significant influence on their spray and combustion characteristics. Dernotte et al. [16] presents an experimental investigation of the influence of fuel density and fuel viscosity on the flow characteristics and on the spray development process generated from a high pressure diesel injector. Results show that increased fuel viscosity leads to a decrease of the discharge coefficient for low injection pressures while density is the main parameter driving the mass flow rate. The spray pattern is also affected since dense and viscous fuels tend to induce a longer spray tip penetration with a more narrow spray angle.

Som et al. [11] refer that differences in the spray characteristics of biodiesel and diesel fuels are more pronounced for evaporating sprays compared to those for non-evaporating 
sprays. This is due to the higher boiling temperature and higher heat of vaporization of biodiesel, implying that vaporization properties rather than fuel physical properties, such as density, viscosity, and surface tension, have a significant influence on spray behaviour.

Fuel injection pressure and fuel injection timing play a main role in ignition delay and combustion characteristics of the engine. Experiments were conducted in order determine the effect of fuel injection pressure on the injection rate of different biodiesel blends [13]. Results show that the fuel injection duration is shortened with increasing injection pressure and the peak injection rate increased with increasing fuel injection pressure. Eloisa Torres-Jimenez et al. [14] investigated fuel injection characteristics of bioethanol-diesel fuel (up to $15 \%$ bioethanol) with the aim of finding the variations in those parameters compared to their respective pure fuel values. Results indicate that increasing bioethanol in diesel fuel shows no significant variations or a slight increase in fuelling, injection timing, injection duration, and mean injection rate and a decrease in injection delay and maximum injection pressure, compared to pure diesel fuel. Investigation was performed on an in-line fuel injection $M$ type system.

Park et al. [15] analysing the effect of blending ethanol into biodiesel fuel on the injection and atomization characteristics. It was revealed that ethanol fuel affects the decrease of the peak injection rate and the shortening of the injection delay due to the decrease of fuel properties.

The review of the literature have shown that there is lack of discussed data on the effect of diesel-ethanol fuel blends on the fuel injection characteristics using common rail injection system. The aim of the research was to investigate the injection characteristics of diesel-ethanol fuel blends in high pressure injection system.

\section{Materials and method}

A blends with $5 \% \mathrm{v} / \mathrm{v}$ ethanol and $95 \% \mathrm{v} / \mathrm{v}$ diesel fuel (DE5), 10\% v/v ethanol and 90\% v/v diesel fuel (DE10), 15\% $\mathrm{v} / \mathrm{v}$ ethanol and $85 \% \mathrm{v} / \mathrm{v}$ diesel fuel (DE15) and low sulphur diesel fuel (DF) as a reference fuel were used in this study. Diesel fuel class 1, was produced at the manufactory "Orlen Lietuva" and its quality parameters satisfied requirements EN 590:2014+AC. Anhydrous ethanol (E) was brought from the producer "Biofuture" Ltd. and its parameters corresponded to standard EN 15376:2009. The properties of the tested fuels and its blends are presented in Table 1. Only that fuels properties were of interest in this study.

Figure 1 presents schematic diagram of the experimental setup. It consists of two parts: the fuel injection system and injection rate measuring system. The fuel injection system includes a high pressure pump, a rail, injector and electronic unit to control injection pressure. The injector nozzle has 6 holes and the diameter of each hole is $0.24 \mathrm{~mm}$. The NI PXIe 1062Q system with DI Driven D000020 module was used to control injection process. Injector was controlled by a peak current of 26.0 A and a holding current of $14.0 \mathrm{~A}$.

The fuel injection rates were measured according Bosch method [17]. The injection rate measuring system included
Table 1. Fuel properties

\begin{tabular}{|l|c|c|}
\hline Parameter & Density at $30^{\circ} \mathrm{C}\left[\mathrm{kg} / \mathrm{m}^{3}\right]$ & $\begin{array}{c}\text { Kinematic viscosity } \\
\text { at } 30^{\circ} \mathrm{C},\left[\mathrm{mm}^{2} / \mathrm{s}\right]\end{array}$ \\
\hline DF & 818.0 & 2.41 \\
\hline E & 797.4 & 1.48 \\
\hline DE5 & 815.5 & 2.21 \\
\hline DE10 & 813.1 & 2.14 \\
\hline DE15 & 810.7 & 2.11 \\
\hline
\end{tabular}

on adapter for mounting of the injector, a measuring tube $5 \mathrm{~m}$ in length, orifice, following tube and check valve. The injection rate measuring method is based on measuring a dynamic increase in pressure produced by the fuel injection into measuring tube filled with fuel. The orifice between measuring tube and following tube adjusts the amplitude of the pressure wave reflections at the end of the measuring tube. The dynamic pressure increase is proportional to the injection rate:

$$
\dot{\mathrm{m}}=\frac{\mathrm{A}_{\text {tube }}}{\mathrm{a}} \mathrm{p}(\mathrm{t})
$$

where $\dot{m}$ is the mass injection rate, $A_{\text {tube }}$ the cross-sectional area of the measuring tube, $a-$ sound velocity in fuel, $p(t)$ - pressure variation.

The pressure variation in the tube was measured with a piezoelectric pressure sensor type $6052 \mathrm{C}$ (Kistler) coupled to the Kistler charge amplifier-module 5064 with an accuracy of $\pm 0.5 \%$ in the pressure range of $0-25.0 \mathrm{MPa}$. The fuel pressure at the injector inlet was measured by a piezoresistive high-pressure Kistler Inc. sensor 4067A2000 and amplified by an amplifier-module 4665 . Both amplifier-modules were mounted on the signals conditioning platform-compact 2854A. The injector energizing, injection rate, fuel pressure and back pressure signals were recorded by an AVL IndiModul 622 data acquisition device.

The fuels have been injected with the following pressures: $25 \mathrm{MPa}, 50 \mathrm{MPa}, 80 \mathrm{MPa}$ and $100 \mathrm{MPa}$. The injection

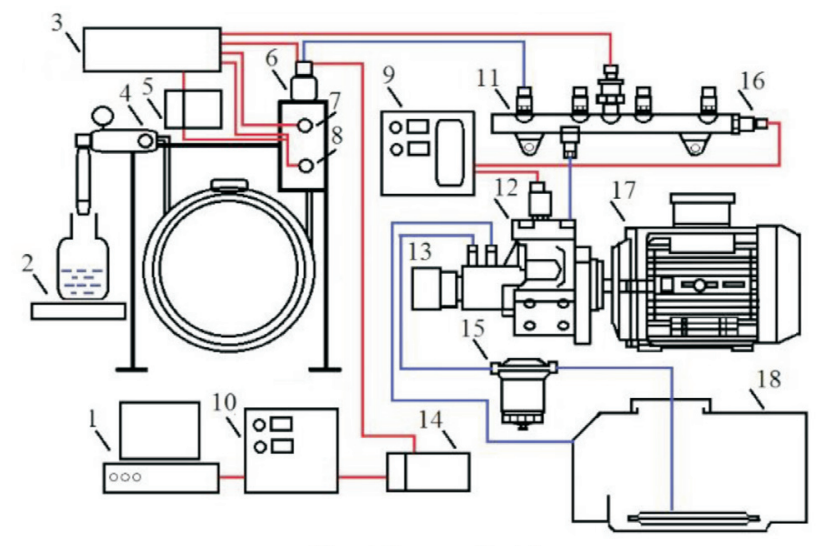

__ Signal line; __ Fuel line

Fig. 1. Scheme of the fuel injection testing stand: $1-\mathrm{PC} ; 2$ - electronic scale; 3 - data acquisition module; 4 - pressure sensor; 5 - charge amplifiermodule; 6 - injector; 7 - temperature sensor; 8 - pressure sensor; 9 - fuel pressure control unit; 10 - injector driver; 11 - common rail; 12 - high pressure fuel pump; 13 - fuel pressure regulator; 14 - NI 9161 chassis; 15 - fuel filter; 16 - rail pressure sensor; 17 - electric motor; 18 - fuel tank 
duration were $2.6 \mathrm{~ms}, 1.5 \mathrm{~ms}, 1.1 \mathrm{~ms}$ and $1.0 \mathrm{~ms}$. The back pressure in the tube was adjusted to $4.0 \mathrm{MPa}$ in order to simulate injection pressure corresponding to the real value of the pressure in the engine combustion chamber during injection.

The results of 100 injection cycles were recorded and averaged for the analysis. The injection quantity was obtained from the mean value of 1000 continuous injections, measured by a precision scale.

The discharge coefficient $\mathrm{Cd}$ was calculated by dividing the measured mass flow rate by the theoretical mass flow rate.

Temperature of the injected fuel was measured with Pt100 sensor and it remained above $30^{\circ} \mathrm{C}$ during experiments.

\section{Results and discussion}

Fuel injection process in Diesel engines plays important role in processes of the in-cylinder combustible mixture formation, ignition, combustion and formation of emissions [2].

Figure 2 shows the injection rate profile of all fuel tested at various injection pressures and energizing duration. When the injection pressure increased, the maximum injection rate increased for all tested fuels. But at the same injection conditions, the peak injection rate of diesel-ethanol blends were lower compared to diesel fuel. At injections pressure of $25 \mathrm{MPa}$ the maximum injection rate of DE5, DE10 and
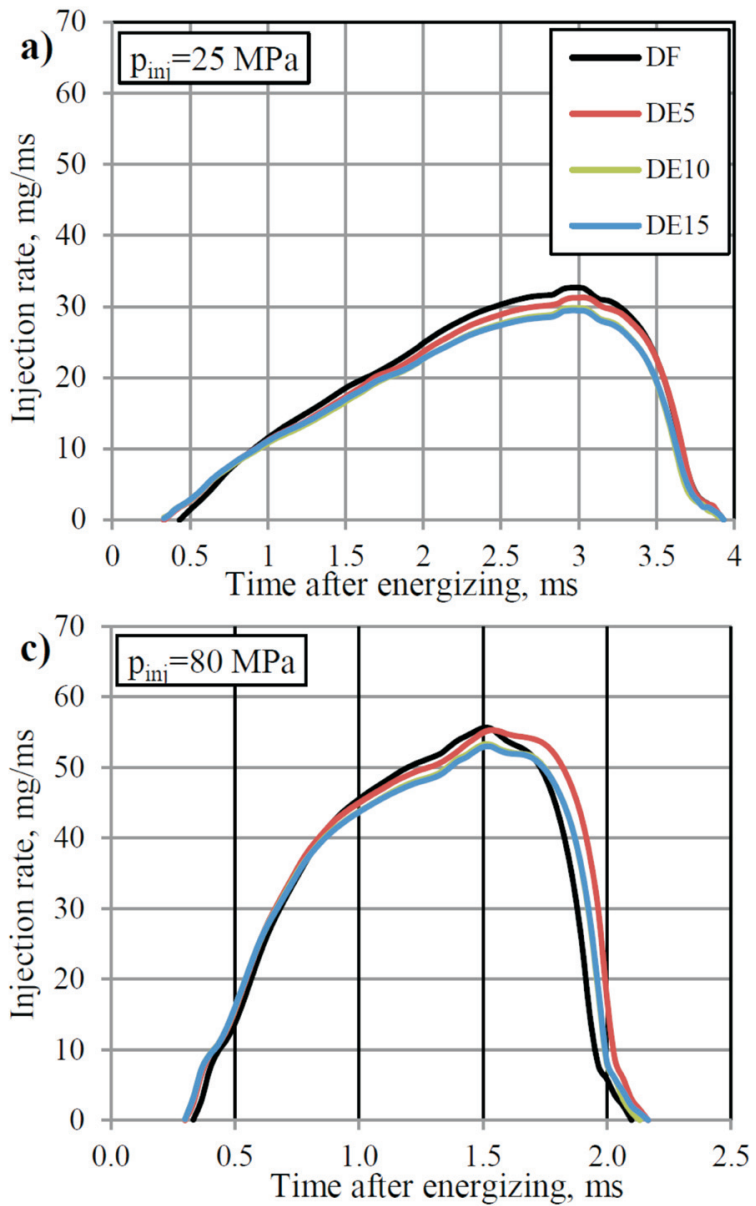

DE15 blends were lower compared to diesel fuel by $4.2 \%$, $8.7 \%$ and $9.8 \%$ correspondently. By increasing injection pressure this difference decreases. Moreover, the biggest reduction of peak injection rate was obtained for DE5 blend. Increasing ethanol amount in the fuel blend had a significant influence on the injection rate characteristic. Decreasing of the peak injection rate of ethanol blended fuels is caused by lower its density.

When the injection pressure was increased, the time to reach the maximum injection rate was advanced for all fuels (Fig. 2). Furthermore, it can be seen that the injection rate of diesel fuel, in spite of higher density and viscosity, has the highest rising slope after the start of injection, while diesel-ethanol blends show a smoother injection rate shape. Possibly, the higher bulk modulus of compressibility of diesel fuel leads to faster nozzle needle move-up.

Figure 3 shows ethanol effect on injection delay at different injection pressure. The injection delay is the time interval between the start of energizing and the start of injection that was obtained from injection rate characteristics. At injection pressure of $25 \mathrm{MPa}$ the injection delay for diesel fuel was $0.43 \mathrm{~ms}$ and for all diesel-ethanol blends $0.33 \mathrm{~ms}$. When the injection pressure increased to $50 \mathrm{MPa}$, the injection delay decreased to $0.37 \mathrm{~ms}$ for diesel fuel and to $0.30 \mathrm{~ms}$ for all diesel-ethanol blends. Increasing the pressure has reduced
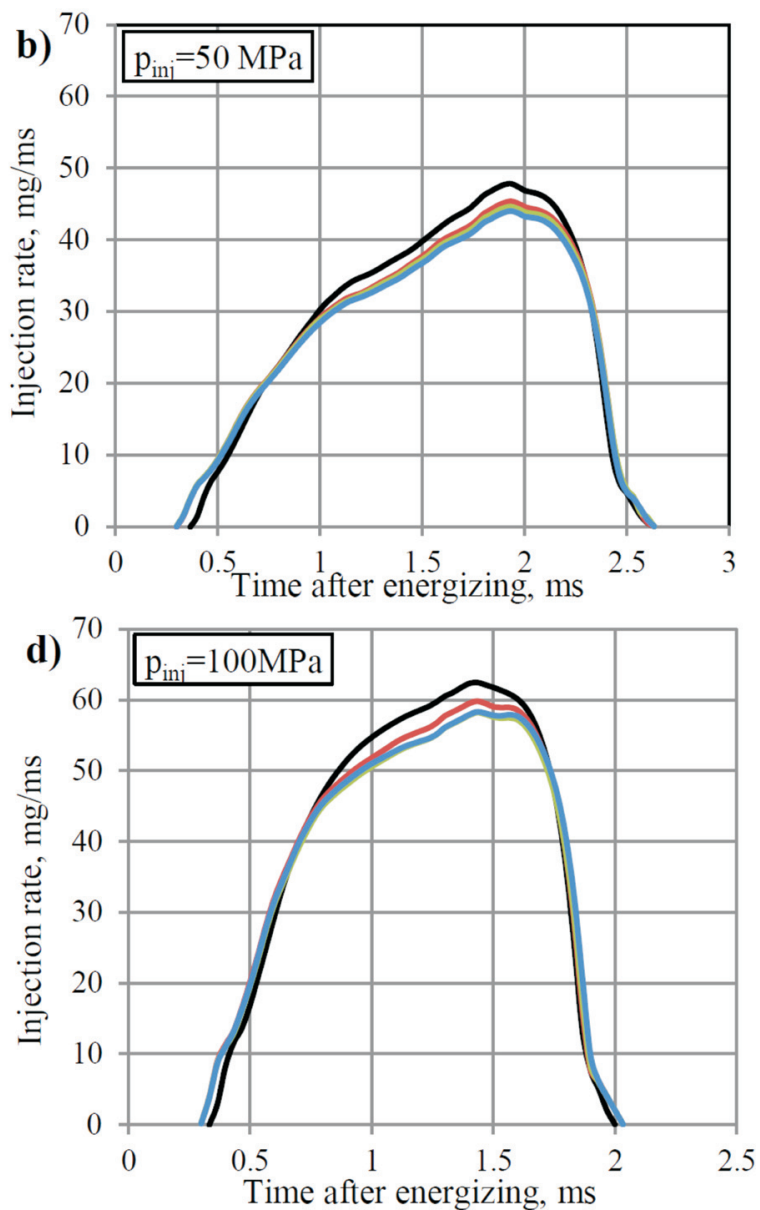

Fig. 2. Effect of the injection pressure and fuel type on the injection rate: back pressure $4.0 \mathrm{MPa} ; \mathrm{a}-\mathrm{t}_{\mathrm{en}}=2.6 \mathrm{~ms} ; \mathrm{b}-\mathrm{t}_{\mathrm{en}}=1.5 \mathrm{~ms} ; \mathrm{c}-\mathrm{t}_{\mathrm{en}}=1.1 \mathrm{~ms}$; $\mathrm{d}-\mathrm{t}_{\mathrm{en}}=1.0 \mathrm{~ms}$ 


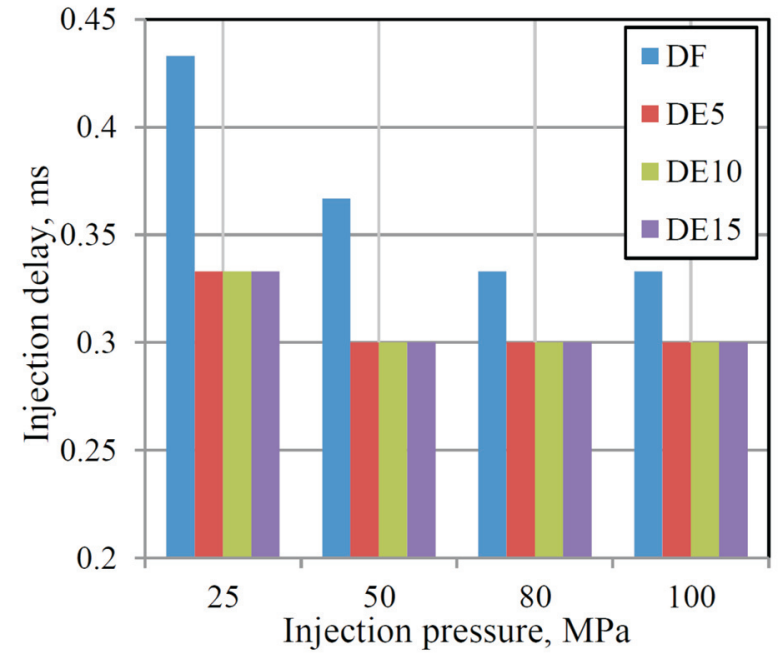

Fig. 3. Effect of the injection pressure on the injection delay

the injection delay. By increasing the injection pressure up to $80.0 \mathrm{MPa}$, the injection delay of diesel fuel slightly decreased to $0.33 \mathrm{~ms}$ and of fuel blends remained unchanged. The injection delay was not affected by increasing pressure up to $100 \mathrm{MPa}$. The injection delay was constant at the same injection pressure for all fuels tested, regardless of the energizing duration.

In contrast to the mechanically controlled injection systems, common rail injector needle rise does not depend on the pump-induced pressure rise, but on the pressures acting on control plunger and nozzle needle difference after the solenoid energizing. The lower density and viscosity of diesel-ethanol blends are able to increase the fuel flow processes and caused shorter injection delay than diesel fuel. Furthermore, the decreased dynamic viscosity of ethanol blended fuel reduced the friction between the fuel and nozzle wall, then affects the injection delay too.

Real fuel injection duration was obtained by analysing injection rate characteristics, and it is the time interval between the start and the end of injection. Figure 4 shows, the injection duration for all test fuels does not differ significantly.

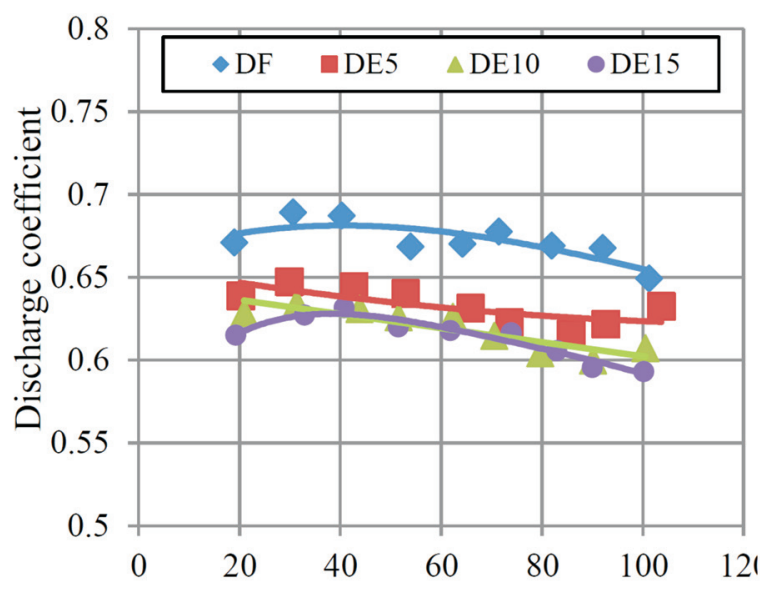

Injection pressure, $\mathrm{MPa}$

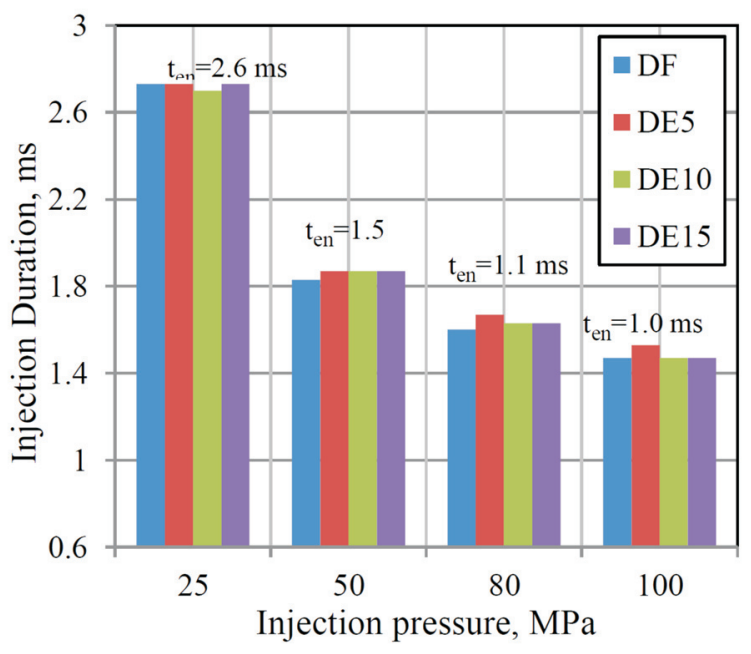

Fig. 4. Injection duration versus injection pressure for different test fuels

Moreover, the real injection duration in all cases was longer than the energizing duration of the injector. The injection duration was longer by $5.0 \%, 24.7 \%, 48.2 \%$ and $47.0 \%$ at injection pressure $25 \mathrm{MPa}, 50 \mathrm{MPa}, 80 \mathrm{MPa}$ and $100 \mathrm{MPa}$ correspondently. The real injection duration becomes longer than the energizing duration due to the response time of the injector solenoid for the control signal.

Figure 5 shows the effect of the injection pressure and ethanol content in fuel blends on the discharge coefficient Cd. It can be seen that with increasing injection pressure, discharge coefficient slightly decreasing for all fuels tested. Despite the lower ethanol density and viscosity, by increasing the ethanol amount in the blend, $\mathrm{Cd}$ decreases. Discharge coefficient for DE5 was by about $5.9 \%$ lower than that for diesel fuel. Increasing ethanol amount in the fuel blend up to $10 \%$ (DE10 Blend), reduced Cd by $2.2 \%$, while the increase of ethanol amount in the fuel blend up to $15 \%$, decreased the discharge coefficient by $0.86 \%$ approximately. Discharge rate decreases are probably related to the fact that the fuel flow is in the cavitation's regime. As the injection pressure is increased, the amount of cavitation is increased, and $\mathrm{C}_{\mathrm{d}}$

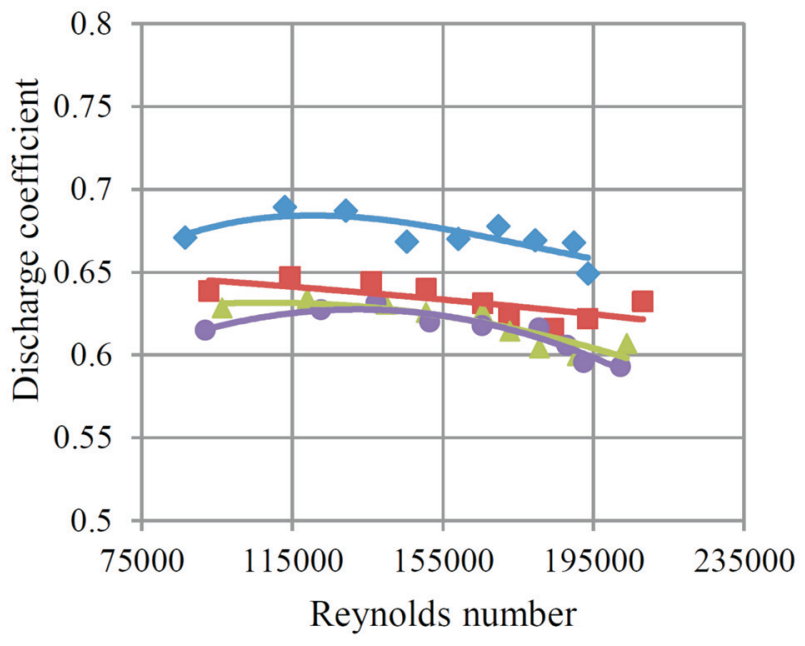

Fig. 5. Discharge coefficient versus injection pressure and Reynolds number for different fuels 
decreased. The vapour pressure of ethanol is higher than diesel fuel. Cavitation occurs when the local pressure is lower than the vapour pressure of the fuel. Hence, increasing in vapour formation can be expected for diesel-ethanol blends, which in turn increases cavitation and decreases discharge coefficient.

\section{Conclusions}

The effect of ethanol additive in diesel fuel on the fuel injection characteristics was experimentally investigated. The injection rate, cycle quantity and the flow losses through the injector nozzle were investigated at $25 \mathrm{MPa}, 50 \mathrm{MPa}$, $80 \mathrm{MPa}$ and $100 \mathrm{MPa}$ injection pressures.
As the research results show, the peak injection rate of diesel-ethanol blends are lower compared to diesel fuel. Furthermore, the injection rate of diesel fuel has the highest rising slope after the start of injection compared to dieselethanol blends.

The injection delay for ethanol blended fuel was shorter by $23 \%, 18.9 \%$ and $9.0 \%$ than for diesel fuel at $25 \mathrm{MPa}$, $50 \mathrm{MPa}$ and $80 \mathrm{MPa}$ injection pressures correspondently. The injection duration in all cases was longer than the energizing duration of the injector and for all test fuels does not differ significantly.

The discharge coefficients of diesel-ethanol blends were lower than those of diesel fuel: about $5 \%, 7.2 \%$ and $8.0 \%$ for the blends DE5, DE10 and DE15 correspondently.

\section{Nomenclature}

$\dot{\mathrm{m}} \quad$ Mass flow rate

a Sound velocity in fuel

$\mathrm{p}(\mathrm{t}) \quad$ Dynamic pressure
$\mathrm{C}_{\mathrm{d}} \quad$ Discharge coefficient

$t_{\mathrm{en}} \quad$ Injector energizing duration

\section{Bibliography}

[1] EC European Commission, et al. White Paper roadmap to a single European transport area towards a competitive and resource efficient transport system. COM, 2011, 144.

[2] Heywood J.B. Internal combustion engine fundamentals (vol. 930). New York: McGraw-Hill, 1988.

[3] Edwards R., Larive J.F., Rouveirolles P. Well-to-wheels analysis of future automotive fuels and power-trains in the European context. Well-to-Wheels report, European Commission Joint Research Centre, January 2001, p. 1-60.

[4] Boudy F., Seers P. Impact of physical properties of biodiesel on the injection process in a common-rail direct injection system. Energy Conversionand Management, 50(12), 2905-2912, 2009,

[5] Rakopoulos D.C., Rakopoulos C.D., Papagiannakis R.G., Kyritsis D.C. Combustion heat release analysis of ethanol or n-butanol diesel fuel blends in heavy-duty DI diesel engine. Fuel, 90 (5), 1855-1867, 2011.

[6] Labeckas G., Slavinskas S., Mažeika M. The effect of ethanol-diesel-biodiesel blends on combustion, performance and emissions of a direct injection diesel engine. Energy Conversion and Management, 2014, (79), 698-720.

[7] Rakopoulos D.C., Rakopoulos C.D., Kakaras E. C., Giakoumis E.G. Effects of ethanol-diesel fuel blends on the performance and exhaust emissions of heavy duty DI diesel engine. Energy Conversion and Management, 2008, 49(11), 3155-3162.

[8] Hansen A.C., Zhang Q., Lyne P.W. Ethanol-diesel fuel blends - a review. Bioresource technology, 2005, 96 (3), 277-285.

[9] Torres-Jimenez E., Jerman M.S., Gregorc A., Lisec I., Dorado M.P., Kegl B. Physical and chemical properties of ethanol-diesel fuel blends.Fuel, 2011, 90 (2), 795-802.

Slavinskas Stasys, DSc., DEng. - Professor in the Faculty of Agricultural Engineering at Aleksandras Stulginskis University in Kaunas, Lithuania.

e-mail: stasys.slavinskas@asu.lt
[10] Weber de Menezes E., da Silva R., Cataluna R., Ortega R.J. Effect of ethers and ether/ethanol additives on the physicochemical properties of diesel fuel and on engine tests. Fuel, 2006, 85 (5), 815-822.

[11] Chakravarthy K., McFarlane J., Daw S.C., Ra Y., Reitz R.D. Physical properties of soy bio-diesel and implications for use of biodiesel in diesel engines. SAE Paper No. 2007-01-0430.

[12] Som S., Longman D.E., Ramirez A.I., Aggarwal S.K. A comparison of injector flow and spray characteristics of biodiesel with petrodiesel. Fuel, 2010, 89 (12), 4014-4024.

[13] Agarwal A.K., Dhar A., Gupta J.G., Kim W.I., Choi K., Lee C.S., Park S. Effect of fuel injection pressure and injection timing of Karanja biodiesel blends on fuel spray, engine performance, emissions and combustion characteristics. Energy Conversion and Management, 2015, 91, 302-314.

[14] Torres-Jimenez E., Dorado M.P., Kegl B. Experimental investigation on injection characteristics of bioethanol-diesel fuel and bioethanol-biodiesel blends. Fuel, 2011, 90(5), 1968-1979.

[15] Park Su Han, Suh Hyun Kyu, Lee Chang Sik. Nozzle flow and atomization characteristics of ethanol blended biodiesel fuel. Renewable energy, 2010, 35.1: 144-150.

[16] Dernotte J., Foucher F., Hespel C., Houille S., MounaïmRousselle C. Experimental study of the effect of fuel properties on the diesel injection process. In Proceedings of the European Combustion Meeting 2011.

[17] Bosch W. The fuel rate indicator: a new instrument for display of the characteristic of individual injection. SAE Paper 660749; 1966.

[18] Park, Su Han; Suh, Hyun Kyu, Lee, Chang Sik. Nozzle flow and atomization characteristics of ethanol blended biodiesel fuel. Renewable energy, 2010, 35.1: 144-150.

Mickevičius Tomas - PhD student in the Faculty of Agricultural Engineering at Aleksandras Stulginskis University in Kaunas, Lithuania.

e-mail: t.mickevicius@yahoo.com

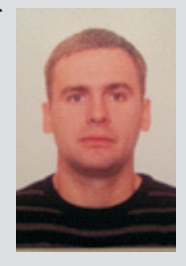

